\title{
MAIN FUNGAL PARTNERS AND DIFFERENT LEVELS OF SPECIFICITY OF ORCHID MYCORRHIZAE IN THE TROPICAL MOUNTAIN FORESTS OF ECUADOR
}

\author{
Juan Pablo SuÁrez ${ }^{1,3} \&$ Ingrid KottKe ${ }^{2}$ \\ ${ }^{1}$ Departamento de Ciencias Naturales, Universidad Técnica Particular de Loja, San Cayetano Alto s/n \\ C.P. 1101 608, Loja, Ecuador* \\ ${ }^{2}$ Plant Evolutionary Ecology, Institute of Evolution and Ecology, Eberhard-Karls-University Tübingen, \\ Auf der Morgenstelle 1, 72076 Tübingen, Germany; retired \\ ${ }^{3}$ Corresponding author: jpsuarez@utpl.edu.ec
}

\begin{abstract}
Orchids are a main component of the diversity of vascular plants in Ecuador with approximately 4000 species representing about $5.3 \%$ of the orchid species described worldwide. More than a third of these species are endemics. As orchids, in contrast to other plants, depend on mycorrhizal fungi already for seed germination and early seedling establishment, availability of appropriate fungi may strongly influence distribution of orchid populations. It is currently debated if green orchids depend on specific mycobionts or may be equally promoted by a broad spectrum of mycorrhizal fungi, discussion mostly based on data from temperate regions. Here we summarize results obtained from broad scale investigations in the tropical mountain rain forest of Ecuador revealing associations with members of Serendipitaceae (Sebacinales), Tulasnellaceae, Ceratobasidiaceae (Cantharellales), and Atractiellales. Recent molecular data show that these worldwide spread fungal groups have broad ecological implications and are specifically suited as mycorrhizal fungi of green orchids. We found that main fungal partners and different levels of specificity among orchids and their mycobionts in the tropical mountain forests correspond to findings in other biomes despite the large ecological differences.
\end{abstract}

Key words: Atractiellales, Ceratobasidiaceae, epiphytic orchids, mycobionts, Serendipitaceae, Tulasnellaceae

Introduction. Interaction between orchids and their mycorrhizal fungi is characterized by production of thousands of tiny seeds lacking carbohydrate reserves. Colonization of a seed by a suitable mycorrhizal fungus is, thus, vital for successful germination, growth and establishment of orchids in nature. The associations with mycorrhizal fungi remain when orchids become photosynthetic (Dearnaley et al. 2012). The extent to which mycobionts support growth of adult orchids in nature is unknown, but the maintenance of the mycobionts is, without doubt, crucial for their juveniles. It was shown that success of seedling establishment is affected by occurrence of mature plants, despite the easy far-distance transport of orchid seeds (Jacquemyn et al. 2007; Jersákovà \& Malinová 2007; Riofrío et al. 2013). It is under current debate if orchid species depend on specific mycobionts or can equally or better be promoted by a broad spectrum of fungi (Kartzinel et al. 2013; Kottke et al. 2013; McCormick \& Jacquemyn 2014). Narrow, specific association might be more efficient (Kiers et al. 2011) and favor propagation of the respective plant and mycobiont against competing species, while a broader mutualistic interaction might be safer in long term survival and distribution. Thus, knowledge on identity of fungal mycobionts and degree of specificity in symbioses is of interest to understand life history and distribution of orchids and a precondition for conservation efforts in such diverse places like the mountain forests of Ecuador where orchids, with approximately 4000 species, constitute about $25 \%$ of native vascular plants (Dodson 2005; Neill 2012). Comprehensive molecular studies on the mycobionts of terrestrial and epiphytic orchids were therefore carried out in the tropical mountain forest of Southern Ecuador (Kottke et al. 2010, 2013; Riofrío et al. 2013; Suárez et al. 2006; Suárez et al. 2008; Suárez 
et al. 2016). Results are summarized here and recent molecular phylogenetic and physiological data of the respective fungal groups are compiled to discuss the findings.

\section{Main fungal partners associated with tropical} orchids. The autotrophic terrestrial and epiphytic orchids in the tropical mountain rain forest were found associated with a limited range of Basidiomycota in the Serendipitaceae (Sebacinales), Tulasnellaceae and Ceratobasidiaceae (Cantharellales), and Atractiellomycetes (Atractiellales) (Kottke et al. 2010, 2013; Otero et al. 2002; Otero et al. 2007; Suárez et al. 2006, 2008, 2016). Tulasnellaceae were the most species rich and most abundant group. All of these fungal groups produce cryptic fruiting structures, which hinder their taxonomic resolution by morphological characters, but molecular approach gives well supported insights at high resolution level (Oberwinkler et al. 2006, 2013a, Oberwinkler et al. 2013b, 2014; Cruz et al. 2016). The nuclear ribosomal RNA locus, in particular the highly variable internal transcribed spacer region including 5.8S (nrITS-5.8S) is among the most widely used locus for phylogenetic studies in fungi and was recently proposed as the universal barcode region for fungi (Schoch et al. 2012). The nrDNA are multi-copy genes and therefore easily amplified from environmental samples. Large numbers of sequences were thus obtained from our samples and analyzed by molecular phylogenetic models including all available data from gene bank. Considering also literature on molecular systematics and whole genome studies of Agaricomycotina (Basidiomycota) we may now better understand why just these fungal groups became orchid mycobionts (Hibbet \& Matheny 2009; Kohler et al. 2015).

Sebacinales - Sebacinales are a basal lineage in Agaricomycotina (Basidiomycota) and include root endophytes, saprotrophic species and species forming mycorrhizal associations (Weiss et al. 2004). Recently, Sebacinales were divided in two sister families: Sebacinaceae, previously Sebacinales subgroup A, and Serendipitaceae, previously Sebacinales subgroup B (Weiss et al. 2016). Members of Sebacinaceae form ectomycorrhizae with diverse tree species (Avis et al. 2003; Glen et al. 2002; Kennedy et al. 2003;
Shefferson et al. 2005; Tedersoo et al. 2006; Walker et al. 2005; Weiss et al. 2004) including tripartite associations with achlorophyllous and mixotrophic orchids (Julou et al. 2005; McKendrick et al. 2002; Selosse et al. 2004; Selosse et al. 2002; Taylor et al. 2003; Urban et al. 2003; Warcup 1971). Sebacinoid mycobionts from green orchids, including epiphytic orchids, appear in Serendipitaceae (Suárez et al. 2008). The same was found for Andean Ericaceae (Setaro et al. 2006a, 2006b).

Cantharellales - Members of Tulasnellaceae and Ceratobasidiaceae are placed in Cantharellales, a basal lineage in Agaricomycotina (Basidiomycota), which contains nearly exclusively saprotrophs or mutualistic biotrophs (Hibbett et al. 2007, 2014; Veldre et al. 2013). Tulasnelloid fungi are worldwide spread, producing inconspicuous, resupinate basidiomata on rotten wood or bark of tree branches (Cruz et al. 2014; Cruz et al. 2016; Roberts 1999). Tulasnellaceae form mycorrhizae with a broad spectrum of plants, including mycorrhiza-like association with Aneuraceae (liverworts) thallus (Kottke et al. 2003; Krause et al. 2011) tripartite associations with the heterotrophic liverwort species Cryptothallus mirabilis and with surrounding trees as ectomycorrhizal partners (Bidartondo et al. 2003). Tulasnella was also found associated with Graffenrieda emarginata (Melastomatacecae) forming a superficial layer on arbuscular mycorrhizas (Haug et al. 2004). Most importantly, however, Tulasnella species are the most frequent and widespread mycobionts of autotrophic orchids (reviewed by Kottke \& Suárez 2009 and Dearnaley et al. 2012). While only few named Tulasnella species are reported as forming mycorrhiza with orchids, molecular phylogeny revealed a large number of genotypes, but also inconsistencies in species concepts and taxonomy challenging comparative ecological studies (Cruz et al. 2011, 2014, 2016). These recent studies on fresh samples of basidiomata showed however, that molecular approach using the ITS-5.8 region and a threshold of $4 \%$ up to $8 \%$ variability gives well supported clades considered as corresponding to species level.

The genera Ceratobasidium and Thanatephorus along with their Rhizoctonia anamorphs form a 
group of closely related fungal taxa in the family Ceratobasidiaceae. A recent phylogenetic analysis revealed ten groups within the Ceratobasidiaceae (González et al. 2016). Species within the Ceratobasidium-Thanatephorus complex are known as crop pathogens but also as forming mycorrhizae with orchids and trees (Tedersoo et al. 2010). Delineating species in these groups has been problematic, efforts to solve this situation included anastomosis groups and molecular data (Oberwinkler et al. 2013b). Studies reporting the presence of members of Ceratobasidiaceae from tropical orchids remain scarce. Using isolation-dependent methods orchid species Coppensia doniana, Tolumnia variegata, Ionopsis utricularioides and Psygmorchis pusilla (tribe Cymbidieae) were shown to be predominantly associated to Ceratobasidiaceae (Valadares et al. 2015; Otero et al. 2002, 2004). However, using isolation-independent methods, members of Ceratobasidiaceae were absent in species of Pleurothallis, Stelis and Epidendrum (tribe Epidendreae) (Suárez et al. 2006, 2008; Kottke et al. 2010; Riofrío et al. 2013).

Atractiellales - Atractiellales belong to the subphylum Pucciniomycotina (Rust fungi), which comprises mainly parasites and to a lesser extent presumed saprophytes (Aime et al. 2006). The phylogenetic position of the mycobionts among potential saprophytes may indicate physiological flexibility from saprophytism to mutualism, as required for orchid mycobionts (Rasmussen \& Rasmussen 2009). So far only three genotypes (operational taxonomic units, OTUs) of Atractiellomycetes were shown by combined ultrastructural and molecular investigations to form mycorrhiza with terrestrial and epiphytic orchids (Kottke et al. 2010; Riofrío et al. 2013; Suárez et al. 2016). Experimental proof for nutritional support of protocorms is, however, still lacking.

\section{Orchid-mycobiont interaction with different} levels of specificity in the tropical mountain forest. Although a high number of orchid species have been recorded, studies on their mycorrhizal fungi are still scarce (Dearnaley et al. 2012), and in most cases, only few individuals per population have been sampled. Factors as orchid recruitment, seed dispersal limitations and availability of suitable fungal partner are affecting the distribution of orchids at regional and local scales and may disguise specificities among plants and fungi. Our studies were concentrated on the conditions of tropical mountain rain forest where intensive sampling was carried out on epiphytic and terrestrial species. Molecular data revealed narrow preferences to broad sharing of partners.

In a pioneer study by Suárez et al. (2006) in the mountain forests of Zamora-Chinchipe of Ecuador, using a combination of fungal isolation and fungalindependent investigations, differences in the number of mycorrhizal fungal partners were found among three Stelis and one Pleurothallis species, two closely related genera (subtribe Pleurothallidinae, tribe Epidendreae). Preferences were evident in case of $S$. concinna, where the highest number of plant individuals was investigated, but the lowest number of fungi was detected. Stelis concinna was associated with only one member of Serendipitaceae and two members of Tulasnellaceae, two of these showing a wide elevation distribution range (Suárez et al. 2006). Beside these preferences, a broad sharing of mycobionts was observed among Stelis and Pleurothallis species (Suárez et al. 2008) potentially explained by their close phylogenetic relationship (Pridgeon, Solano \& Chase 2001).

Riofrío et al. (2013) carried out a study in a nearby site, focusing on within-population variation of mycorrhizal associations of the epiphytic orchid Epidendrum rhopalostele (subtribe Laeliinae, tribe Epidendreae). Individuals were associated with only two different clades of closely related Tulasnella. The two clades were spatially randomly distributed showing no segregation patterns, both clades were related to the Tulasnella isolated from Stelis and Pleurothallis by Suárez et al. (2006), but corresponded to distinct genotypes.

Kottke et al. (2010) showed that three Atractiellales genotypes, closely related to Infundibura, formed mycorrhizas with many terrestrial and epiphytic orchid species in the Andean tropical forest and regenerating habitats. Similar broad sharing was found for Tulasnella and Seredipita genotypes from the same area (Kottke et al. 2013).

A study carried out near the town of Baños, Tungurahua province, far from Zamora-Chinchipe 
area, revealed that Teagueia morphospecies (subtribe Pleurothallidinae, tribe Epidendreae) were associated with members of Tulasnellaceae and Atractiellales. The phylogenetic analysis of ITS-5.8S sequences of members of Tulasnellaceae showed sequences in four clades. Sequences from the previous study by Suárez et al. (2006) are closely related to these clades. The obtained Atractiellales sequences were identical to "phylotype I" as found by Kottke et al. (2010) from the previous study in Zamora-Chinchipe, Ecuador. Results show up to three different phylogenetic species of mycobionts associated to one Teagueia species suggesting high potential for sharing mycobionts among Teagueia spp. All the detected mycobionts had wide geographical distribution.

Discussion. The molecular phylogenetic based investigations of orchid mycobionts in the tropical mountain rain forest area of Southern Ecuador revealed the well established fungal groups, Serendipidaceae, Tulasnellaceae and Ceratobasidiaceae. Additionally, Atractiellales were found as widespread mycobionts. The latter can be found in some data sets of previous investigations, but were not seriously considered before. Although we cannot definitely exclude that further fungal groups may be detected in future, we may ask why just members of these few fungal families are suitable mycobionts of green orchid. The vast majority of plants form mycorrhizae with Glomeromycota, obligate symbionts with no access to extraradical sugars. Thus, these mycobionts are unsuitable to feed the orchid protocorm. Mycobionts in Agaricomycetes, however, derived from saprotrophic relatives multiple times and the orchid mycorrhizal groups, in basal position of Agaricomycetes, preserved some genes for decay enzymes (Hibbett et al. 2007; Kohler et al. 2015). Preservation of the respective genes means sufficient organic matter decay for acquiring carbon and nitrogen to feed the orchid protocorm without attacking living cells in a parasitic manner. According with these capabilities, these fungi are prepared to grow on tree bark (Kartzinel et al. 2013) and may additionally profit from the water-retention capacity of the velamen covering roots of epiphytic orchids. The particular conditions in the epiphytic habitat may have potentially supported adaptations to the specific groups of mycorrhizal fungi. The life history sets
Orchidaceae apart from all other Monocotyledonae and was obviously facilitated by switching from Glomeromycota to mainly these Agaricomycetes in Basidiomycota as mycorrhizal fungi. We may consider this switch as a synapomorphy of the family (Yukawa, Ogura-Tsujita, Shefferson \& Yokoyama. 2009).

Another question under debate concerns about potential specificity among orchids and mycobionts. Most investigations focused on rather species poor orchid populations in temperate areas (McCormick \& Jacquemyn 2014). It was generally found that orchid rarity was unrelated to specificity, but coexisting, terrestrial orchid populations were associated with distinct mycobiont communities. In case of tropical epiphytic orchids, availability of appropriate fungi may be especially critical for plant survival under the restricted conditions of shortage of water or organic and inorganic nutrients (Zotz \& Hietz 2001; Martos et al. 2012; Dearnaley et al. 2012). Fungi may be rare to meet on tree branches and stems, potentially restricted to species adapted to these niches. Accordingly, Martos et al. (2012) found significant differences among epiphytic and terrestrial orchid mycobionts in old world tropical Reunion island. We carried out a comparatively large-scale survey in the new world tropical forest of the Ecuadorian Andes on epiphytic and terrestrial orchids. Our results showed different levels of specificity, ranging from unspecific, multispecies networks to narrow orchid clades associated with few world-wide spread Tulasnella genotypes, and to narrow species-species associations along an elevation gradient or among dense populations of an epiphytic orchid. Species richness, environmental conditions but also sampling efforts and methods of fungal identification may still bias a clear statement on narrow specificity in the wet tropical habitat. More likely, sharing of mycobionts will improve the rate of successful germination of orchid seeds and also promote co-existence of closely related species as observed in the tropical montane rain forest (Kottke et al. 2013).

Acknowledgments. The Universidad Técnica Particular de Loja- UTPL and the Deutsche ForschungsgemeinschaftDFG financed this research. We thank the Reserva Biológica San Francisco for providing research facilities. 


\section{Literature Cited}

Aime, M. C., Matheny, P. B., Henk, D. A., Frieders, E. M., Nilsson, R. H., Piepenbring, M., et al. (2006). An overview of the higher level classification of Pucciniomycotina based on combined analyses of nuclear large and small subunit rDNA sequences. Mycologia, 98(6), 896-905.

Avis, P., McLaughlin, D., Dentinger, B. \& Reich, P. (2003). Long-term increase in nitrogen supply alters aboveand below-ground ectomycorrhizal communities and increases the dominance of Russula spp. in a temperate oak savanna. New Phytologist, 160(1), 239-253.

Bidartondo, M. I., Bruns, T. D., Weiss, M., Sergio, C. \& Read, D. J. (2003). Specialized cheating of the ectomycorrhizal symbiosis by an epiparasitic liverwort. Proceedings of the Royal Society of London, Series B: Biological Sciences, 270(1517), 835-842. http://doi. org/10.1098/rspb.2002.2299

Cruz, D., Suárez, J. P. \& Piepenbring, M. (2016). Morphological revision of Tulasnellaceae, with two new species of Tulasnella and new records of Tulasnella spp. for Ecuador. Nova Hedwigia, 102(3-4), 279-338.

Cruz, D., Suárez, J. P., Kottke, I. \& Piepenbring, M. (2014). Cryptic species revealed by molecular phylogenetic analysis of sequences obtained from basidiomata of Tulasnella. Mycologia, 106(4), 708-722. http://doi. org/10.3852/12-386

Cruz, D., Suárez, J. P., Kottke, I., Piepenbring, M. \& Oberwinkler, F. (2011). Defining species in Tulasnella by correlating morphology and nrDNA ITS-5.8S sequence data of basidiomata from a tropical Andean forest. Mycological Progress, 10(2), 229-238. http:// doi.org/10.1007/s11557-010-0692-3

Dearnaley, J., Martos, F. \& Selosse, M. A. (2012). Orchid Mycorrhizas: Molecular Ecology, Physiology, Evolution and Conservation Aspects. In: B. Hock (Ed.), The Mycota IX: Fungal associations (pp. 207-230). Berlin, Heidelberg: Springer.

Dodson, C. (2005). Native Ecuadorian Orchids, vol IV. 665 pp.

Glen, M., Tommerup, I., Bougher, N. \& O'Brien P.A. (2002) Are Sebacinaceae common and widespread ectomycorrhizal associates of Eucalyptus species in Australian forests? Mycorrhiza, 12, 243-247.

González, D., Rodriguez-Carres, M., Boekhout, T., Stalpers, J., Kuramae, E. E., Nakatani, A. K., et al. (2016). Phylogenetic relationships of Rhizoctonia fungi within the Cantharellales. Fungal Biology, 120(4), 603-619.

Haug, I., Lempe, J., Homeier, J., Weiss, M., Setaro, S. D., Oberwinkler, F. \& Kottke, I. (2004). Graffenrieda emarginata (Melastomataceae) forms mycorrhizas with Glomeromycota and with a member of the
Hymenoscyphus ericae aggregate in the organic soil of a neotropical mountain rain forest. Canadian Journal of Botany, 82(3), 340-356.

Hibbett, D. S., Bauer, R., Binder, M., Giachini, A. J., Hosaka, K., Justo, A., et al. (2014). Agaricomycetes. In: Systematics and Evolution (pp. 373-429). Berlin, Heidelberg: Springer. http://doi.org/10.1007/978-3642-55318-9_14

Hibbett, D. S., Binder, M., Bischoff, J. F., Blackwell, M., Cannon, P. F., Eriksson, O. E., et al. (2007). A higher-level phylogenetic classification of the Fungi. Mycological Research, 111(Pt 5), 509-547. http://doi. org/10.1016/j.mycres.2007.03.004

Hibbett, D. \& Matheny, P. (2009). The relative ages of ectomycorrhizal mushrooms and their plant hosts estimated using Bayesian relaxed molecular clock analyses. BMC Biology, 7(1), 13.

Jacquemyn, H., Brys, R., Vandepitte, K., Honnay, O., Roldán Ruiz, I. \& Wiegand, T. (2007). A spatially explicit analysis of seedling recruitment in the terrestrial orchid Orchis purpurea. New Phytologist, 176(2), 448-459.

Jersákovà, J. \& Malinová, T. (2007). Spatial aspects of seed dispersal and seedling recruitment in orchids. New Phytologist, 176, 237-241.

Julou, T., Burghardt, B., Gebauer, G., Berveiller, D., Damesin, C. \& Selosse, M. A. (2005). Mixotrophy in orchids: insights from a comparative study of green individuals and nonphotosynthetic individuals of Cephalanthera damasonium. New Phytologist, 166(2), 639-653. http://doi.org/10.1111/j.14698137.2005.01364.x

Kartzinel, T. R., Trapnell, D. W. \& Shefferson, R. P. (2013). Highly diverse and spatially heterogeneous mycorrhizal symbiosis in a rare epiphyte is unrelated to broad biogeographic or environmental features. Molecular Ecology, 22(23), 5949-5961. http://doi.org/10.1111/ mec. 12536

Kennedy, P. G., Izzo, A. \& Bruns, T. D. (2003). There is high potential for the formation of common mycorrhizal networks between understorey and canopy trees in a mixed evergreen forest. Journal of Ecology, 91(6), 1071-1080.

Kiers, E.T., Duhamel, M., Beesetty, Y., Mensah, J.A., Franken, O., Verbruggen, E. et al. (2011) Reciprocal rewards stabilize cooperation in the mycorrhizal symbiosis. Science, 333, 880-882.

Kohler, A., Kuo, A., Nagy, L. G., Morin, E., Barry, K. W., Buscot, F., et al. (2015). Convergent losses of decay mechanisms and rapid turnover of symbiosis genes in mycorrhizal mutualists. Nature Genetics, 47(4), 410 415. http://doi.org/10.1038/ng.3223 
Kottke, I., Setaro, S., Haug, I., Herrera, P., Cruz, D., Fries, A., Gawlik, J., Homeier, J., Werner, F.A., Gerique, A. \& Suárez, J.P. (2013) Mycorrhiza networks promote biodiversity and stabilize the tropical mountain rain forest ecosystem: Perspectives for understanding complex communities. In: Ecological Studies (Vol. 221, pp. 187-203). Berlin, Heidelberg: Springer.

Kottke, I. \& Suárez, J.P. (2009) Mutualistic, root-inhabiting fungi of orchids identification and functional types. In: A.M. Pridgeon \& JP Suárez (Ed.), Proceedings of the Second Scientific Conference on Andean Orchids (pp. 84-99). Loja, Ecuador: Universidad Técnica Particular de Loja.

Kottke, I., Suárez, J.P., Herrera, P., Cruz, D., Bauer, R., Haug, I. \& Garnica, S. (2010) Atractiellomycetes belonging to the 'rust' lineage (Pucciniomycotina) form mycorrhizae with terrestrial and epiphytic Neotropical orchids. Proceedings of the Royal Society of London, Series B: Biological Sciences, 277, 1289-1298. doi: 10.1098/repb.2009.1884

Kottke, I., Beiter, A., Weiss, M., Haug, I., Oberwinkler, F. \& Nebel, M. (2003). Heterobasidiomycetes form symbiotic associations with hepatics: Jungermanniales have sebacinoid mycobionts while Aneura pinguis (Metzgeriales) is associated with a Tulasnella species. Mycological Research, 107(Pt 8), 957-968.

Krause, C., Garnica, S., Bauer, R. \& Nebel, M. (2011). Aneuraceae (Metzgeriales) and tulasnelloid fungi (Basidiomycota): a model for early steps in fungal symbiosis. Fungal Biology, 115(9), 839-851. http://doi. org/10.1016/j.funbio.2011.06.013

Martos, F., Munoz, F., Pailler, T., Kottke, I., Gonneau, C. \& Selosse, M. A. (2012). The role of epiphytism in architecture and evolutionary constraint within mycorrhizal networks of tropical orchids. Molecular Ecology, 21(20), 5098-5109. http://doi.org/10.1111/ j.1365-294X.2012.05692.x

McCormick, M. K. \& Jacquemyn, H. (2014). What constrains the distribution of orchid populations? New Phytologist, 202(2), 392-400. http://doi.org/10.1111/ nph.12639

McKendrick, S., Leake, J., Taylor, D. L. \& Read, D. J. (2002). Symbiotic germination and development of the myco-heterotrophic orchid Neottia nidus-avis in nature and its requirement for locally distributed Sebacina spp. New Phytologist, 154(1), 233-247.

Neill D (2012). ¿Cuántas especies nativas de plantas vasculares hay en Ecuador? Revista amazónica: Ciencia y Tecnología, 1,70-83.

Oberwinkler, F., Riess, K., Bauer, R., \& Garnica, S. (2014). Morphology and molecules: the Sebacinales, a case study. Mycological Progress, 13(3), 445-470. http:// doi.org/10.1007/s11557-014-0983-1
Oberwinkler, F., Riess, K., Bauer, R., Selosse, M. A., Weiss, M., Garnica, S. \& Zuccaro, A. (2013a). Enigmatic Sebacinales. Mycological Progress, 12(1), 1-27. http:// doi.org/10.1007/s11557-012-0880-4

Oberwinkler, F., Riess, K., Bauer, R., Kirschner, R. \& Garnica, S. (2013b) Taxonomic re-evaluation of the Ceratobasidium-Rhizoctonia complex and Rhizoctonia butinii, a new species attacking spruce. Mycological Progress, 12, 763-776.

Oberwinkler, F., Kirschner, R., Arenal, F., Villarreal, M., Rubio, V., Begerow, D. \& Bauer, R. (2006) Two new members of the Atractiellales: Basidiopycnis hyalina and Proceropycnis pinicola. Mycologia, 98, 637-649.

Otero, J. T., Ackerman, J. D. \& Bayman, P. (2002). Diversity and host specificity of endophytic Rhizoctonia-like fungi from tropical orchids. American Journal of Botany, 89(11), 1852-1858. http://doi.org/10.3732/ ajb.89.11.1852

Otero, J. T., Flanagan, N. S., Herre, E. A., Ackerman, J. D. \& Bayman, P. (2007). Widespread mycorrhizal specificity correlates to mycorrhizal function in the neotropical, epiphytic orchid Ionopsis utricularioides (Orchidaceae). American Journal of Botany, 94(12), 1944-1950. http://doi.org/10.3732/ajb.94.12.1944

Otero, J. T., Ackerman, J. D. \& Bayman, P. (2004). Differences in mycorrhizal preferences between two tropical orchids. Molecular Ecology, 13(8), 2393-2404. http://doi.org/10.1111/j.1365-294X.2004.02223.x

Pridgeon, A., Solano, R. \& Chase, M. W. (2001). Phylogenetic relationships in Pleurothallidinae (Orchidaceae): combined evidence from nuclear and plastid DNA sequences. American Journal of Botany, 88(12), 2286-2308.

Rasmussen, H. N. \& Rasmussen, F. N. (2009). Orchid mycorrhiza: implications of a mycophagous life style. Oikos, 118(3), 334-345. http://doi.org/10.1111/j.16000706.2008.17116.x

Riofrío, M. L., Cruz, D., Torres, E., De la Cruz, M., Iriondo, J. M. \& Suárez, J. P. (2013). Mycorrhizal preferences and fine spatial structure of the epiphytic orchid Epidendrum rhopalostele. American Journal of Botany, 100(12), 2339-2348.

Roberts, P. (1999). Rhizoctonia-forming Fungi: a taxonomic guide. Royal Botanic Gardens, Kew.

Schoch, C. L., Seifert, K. A., Huhndorf, S., Robert, V., Spouge, J. L., Levesque, C. A., et al. (2012). Nuclear ribosomal internal transcribed spacer (ITS) region as a universal DNA barcode marker for Fungi. Proceedings of the National Academy of Sciences of the United States of America, 109(16), 6241-6246. http://doi. org/10.1073/pnas.1117018109

Selosse, M. A., Faccio, A., Scappaticci, G. \& Bonfante, P. (2004). Chlorophyllous and achlorophyllous 
specimens of Epipactis microphylla (Neottieae, Orchidaceae) are associated with ectomycorrhizal Septomycetes, including Truffles. Microbial Ecology, 47(4), 416-426.

Selosse, M. A., Weiss, M., Jany, J. \& Tillier, A. (2002). Communities and populations of sebacinoid basidiomycetes associated with the achlorophyllous orchid Neottia nidus-avis (L.) L.C.M. Rich. and neighbouring tree ectomycorrhizae. Molecular Ecology, 11(9), 1831-1844.

Setaro, S. D., Kottke, I. \& Oberwinkler, F. (2006a). Anatomy and ultrastructure of mycorrhizal associations of neotropical Ericaceae. Mycological Progress, 5(4), 243-254.

Setaro, S. D., Weiss, M., Oberwinkler, F. \& Kottke, I. (2006b). Sebacinales form ectendomycorrhizas with Cavendishia nobilis, a member of the Andean clade of Ericaceae, in the mountain rain forest of southern Ecuador. New Phytologist, 169(2), 355-365. http://doi. org/10.1111/j.1469-8137.2005.01583.x

Shefferson, R. P., Weiss, M., Kull, T. \& Taylor, D. L. (2005). High specificity generally characterizes mycorrhizal association in rare lady's slipper orchids, genus Cypripedium. Molecular Ecology, 14(2), 613-626. http://doi.org/10.1111/j.1365-294X.2005.02424.x

Suárez, J. P., Weiss, M., Abele, A., Garnica, S., Oberwinkler, F. \& Kottke, I. (2006). Diverse tulasnelloid fungi form mycorrhizas with epiphytic orchids in an Andean cloud forest. Mycological Research, 110, 1257-1270. http:// doi.org/10.1016/j.mycres.2006.08.004

Suárez, J. P., Weiss, M., Abele, A., Oberwinkler, F. \& Kottke, I. (2008). Members of Sebacinales subgroup B form mycorrhizae with epiphytic orchids in a neotropical mountain rain forest. Mycological Progress, 7(2), 7585. http://doi.org/10.1007/s11557-008-0554-4

Suárez, J. P., Eguiguren, J. S., Herrera, P. \& Jost, L. (2016). Do mycorrhizal fungi drive speciation in Teagueia (Orchidaceae) in the upper Pastaza watershed of Ecuador? Symbiosis, 69(3), 161-168. http://doi. org/10.1007/s13199-016-0399-6

Taylor, D. L., Bruns, T. D., Szaro, T. \& Hodges, S. (2003). Divergence in mycorrhizal specialization within Hexalectris spicata (Orchidaceae), a nonphotosynthetic desert orchid. American Journal of Botany, 90(8), 1168-1179.

Tedersoo, L., May, T. W. \& Smith, M. E. (2010). Ectomycorrhizal lifestyle in fungi: global diversity, distribution, and evolution of phylogenetic lineages. Mycorrhiza, 20(4), 217-263. http://doi.org/10.1007/ s00572-009-0274-x

Tedersoo, L., Suvi, T., Larsson, E. \& Kõljalg, U. (2006). Diversity and community structure of ectomycorrhizal fungi in a wooded meadow. Mycological Research, 110(6), 734-748.

Urban, A., Weiss, M. \& Bauer, R. (2003). Ectomycorrhizas involving sebacinoid mycobionts. Mycological Research, 107(1), 3-14.

Valadares, R., Otero, J. T., Correa-Pereira, M. \& Cardoso, E. (2015). The epiphytic orchids Ionopsis utricularioides and Psygmorchis pusilla associate with different Ceratobasidium lineages at Valle del Cauca, Colombia. Acta Botanica Brasilica, 29(1), 40-44.

Veldre, V., Abarenkov, K., Bahram, M., Martos, F., Selosse, M. A., Tamm, H., et al. (2013). Evolution of nutritional modes of Ceratobasidiaceae (Cantharellales, Basidiomycota) as revealed from publicly available ITS sequences. Fungal Ecology, 6(4), 256-268. http://doi. org/10.1016/j.funeco.2013.03.004

Walker, J. F., Miller, O. K. \& Horton, J. L. (2005). Hyperdiversity of ectomycorrhizal fungus assemblages on oak seedlings in mixed forests in the southern Appalachian Mountains. Molecular Ecology, 14(3), 829-838. http://doi.org/10.1111/j.1365294X.2005.02455.x

Warcup, J. (1971). Specificity of mycorrhizal association in some Australian terrestrial orchids. New Phytologist, 70(1), 41-46.

Weiss, M., Selosse, M. A., Rexer, K., Urban, A. \& Oberwinkler, F. (2004). Sebacinales: a hitherto overlooked cosm of heterobasidiomycetes with a broad mycorrhizal potential. Mycological Research, 108(9), 1003-1010.

Weiss, M., Waller, F., Zuccaro, A. \& Selosse, M-A. (2016) Sebacinales - one thousand and one interactions with land plants. New Phytologist, 211(1), 20-40.

Yukawa, T., Ogura-Tsujita, Y., Shefferson, R. P. \& Yokoyama, J. (2009). Mycorrhizal diversity in Apostasia (Orchidaceae) indicates the origin and evolution of orchid mycorrhiza. American Journal of Botany, 96(11), 1997-2009. http://doi.org/10.3732/ ajb.0900101

Zotz, G. \& Hietz, P. (2001). The physiological ecology of vascular epiphytes: current knowledge, open questions. Journal of Experimental Botany, 52(364), 2067-2078. 
LANKESTERIANA • V SCIENTIFIC CONFERENCE ON ANDEAN ORCHIDS 